\title{
Secular change in birthweight of Asian babies born in Birmingham
}

\author{
C L CLARSON, M J BARKER, T MARSHALL, AND B A WHARTON
}

Sorrento Maternity Hospital, Birmingham, and Department of Social Medicine, University of Birmingham

SUMMARY We have studied changes in the birthweight of Asian babies born alive at this hospital between 1968 and 1978. In 1978 Pakistani babies were $139 \mathrm{~g}$ heavier but Indian babies only $25 \mathrm{~g}$ heavier than 10 years earlier. Contributing to these changes were significantly fewer short mothers and primiparae among Pakistanis, and non-significant increases in gestational age and intrauterine growth (that is, weight centile after allowing for gestational age, parity, and maternal height). Among Indians there were significant increases in maternal height and gestational age, but parity was reduced and intrauterine growth did not increase. In both groups there were fewer teenage mothers, but whereas among Pakinstanis birth intervals of less than one year were less common, there was no such reduction among Indian mothers. The secular change suggests that genetic factors are unlikely to be the major reason why Pakistani babies born in Birmingham are lighter than European babies, and that environmental factors play an important role. Efforts to increase birthweight need to consider both the mothers' physical environment during pregnancy and prepregnancy factors influencing growth in childhood, age at first pregnancy, and birth interval. The study shows a need to describe an 'Asian' population with details of their sub-ethnic structure. The sub-ethnic and secular differences further suggest that a single 'Asian' standard for birthweight and intrauterine growth may be inappropriate; the use of international reference data with which all infants may be compared is preferable.

Asian babies born in Asia have a high incidence of low birthweight ${ }^{1-3}$ and Asian babies born in this hospital ${ }^{4}$ and elsewhere in Britain ${ }^{56}$ are on average lighter than European babies. As one approach to identifying programmes that might increase birthweight, we have studied the changes in weight of Asian babies born at this hospital during the last decade and have tried to determine the factors responsible.

The study of immigrant populations is a wellknown biological tool, since it enables the effect of fairly rapid changes to be determined while holding the genetic structure reasonably constant: this was a further reason for the investigation.

\section{Methods}

The study was retrospective. Information was transcribed from the routine clinical records by either M J B or C L C on a standard form. Derived data-for example rate of weight gain, weight centile, etc-were calculated by M J B or C L C and added to the form.
The study population comprised live singleton babies born at Sorrento who were ethnically of Asian origin - that is brown-skinned people who themselves, or whose ancestors, had originated in the Indian sub-continent-stillbirths and twins were excluded. In 1968 there were 268 eligible babies, and all were included. By 1978 the number of Asian births had risen considerably. Partly for resource reasons, and partly to obtain about equal numbers, only every third consecutive eligible baby was included, giving a total for that year of 309.

As analysis progressed, it became clear that there had been a change in the sub-ethnic background of the mothers attending Sorrento, and that the secular change in the characteristics of Pakistani mothers and babies was different from that of Indians. Accordingly, 'Asians' whose sub-ethnic group could not be determined were excluded (10 in 1968 and 11 in 1978). Two sub-ethnic groups were distinguished in 1968: Indian (106 mothers) and Pakistani (152). By 1978 a third group had emerged, East Pakistan having become the independent state of Bangladesh, so that the sample consisted of 70 Indians, 202 


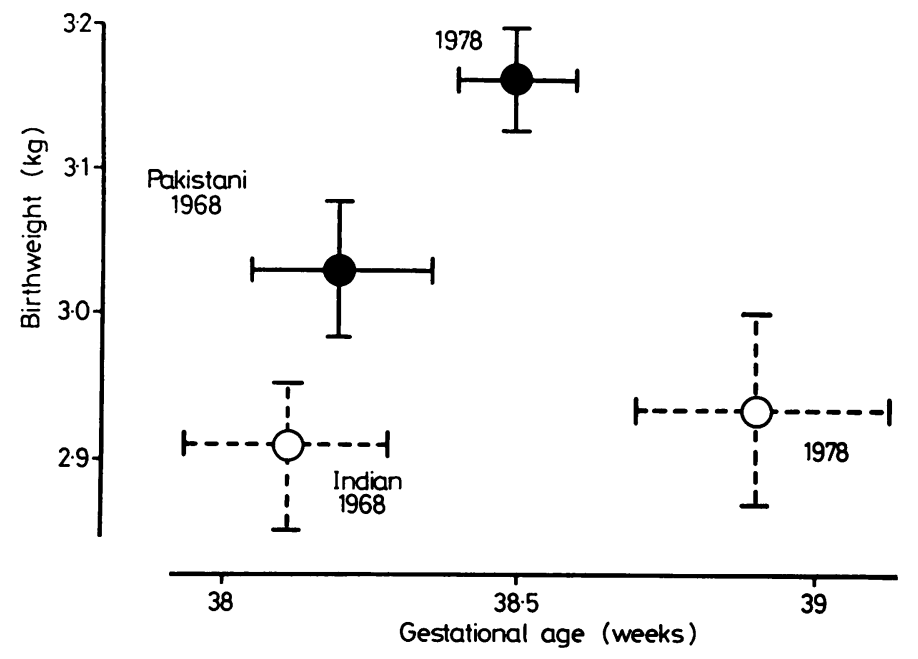

Fig. 1 Birthweight and gestational age (mean $\pm S E$ ) of Pakistani and Indian babies born at Sorrento Maternity Hospital, Birmingham, in 1968 and 1978. Compared with 1968, in 1978 the Pakistani babies were heavier $(P<0.01)$, the increase in gestational age was not significant. Indian babies were not significantly heavier but had a greater gestational age $P<0.05$.

Pakistanis, and 26 Bangladeshi. For the purpose of comparing Indians with 'Pakistanis', or studying secular change, the 1978 Pakistani and Bangladeshi data have been combined. The results from the 1978 Pakistani mothers were also analysed separately but this led to no change in the conclusion drawn.

\section{Results}

Birthweight (Table 1): Pakistani babies were on average $139 \mathrm{~g}$ heavier in 1978 than in 1968; Indian babies were $25 \mathrm{~g}$ heavier.
Major variables affecting birthweight. Fig. 1 and Table 1 show details of the major variables known to affect birthweight-that is gestational age, parity, and maternal height.

\section{Comparison between 1968 and 1978}

Pakistanis. There were fewer very short mothers and fewer primiparae. There was a small non-significant increase in gestational age. In addition, mean birthweight at each gestational age was somewhat higher in 1978.

Table 1 Birthweight and major factors affecting it

\begin{tabular}{|c|c|c|c|c|c|c|}
\hline & \multicolumn{3}{|l|}{ Indian } & \multicolumn{3}{|l|}{ Pakistani } \\
\hline & $\begin{array}{l}1968 \\
(n=106)\end{array}$ & $\begin{array}{l}1978 \\
(n=70)\end{array}$ & $P$ value & $\begin{array}{l}1968 \\
(n=152)\end{array}$ & $\begin{array}{l}1978 \\
(n=228)\end{array}$ & $P$ value \\
\hline $\begin{array}{l}\text { Boys : girls } \\
\text { Birttweight (g) }\end{array}$ & $55: 51$ & $37: 33$ & & $76: 76$ & $111: 117$ & \\
\hline \multicolumn{7}{|l|}{ Birthweight (g) } \\
\hline $\begin{array}{l}\text { Mean } \\
\text { SD }\end{array}$ & 2908 & 2933 & & 3022 & 3161 & $<0.01 \dagger$ \\
\hline SD & 490 & 510 & & 440 & 520 & \\
\hline$<2500 \mathrm{~g}$ & $21(20 \%)$ & $11(16 \%)$ & & $14(9 \%)$ & $16(7 \%)$ & \\
\hline \multicolumn{7}{|l|}{ Gestational age (weeks) } \\
\hline Mean & $38 \cdot 1$ & $38 \cdot 9$ & $=0.06 \ddagger$ & $38 \cdot 2$ & $38 \cdot 5$ & \\
\hline SD & 1.7 & $2 \cdot 1$ & & 1.7 & 1.6 & \\
\hline$<37$ weeks & $20(19 \%)$ & $6(9 \%)$ & $\bumpeq 0.08^{*}$ & $20(13 \%)$ & $22(10 \%)$ & \\
\hline \multicolumn{7}{|l|}{ Previous births } \\
\hline Mean & $2 \cdot 3$ & $1 \cdot 3$ & & $2 \cdot 1$ & $2 \cdot 5$ & \\
\hline SD & $2 \cdot 3$ & 1.4 & & $2 \cdot 0$ & $2 \cdot 2$ & \\
\hline Nil & $35(33 \%)$ & $30(43 \%)$ & & $48(32 \%)$ & $44(19 \%)$ & \\
\hline $1-4$ & $49(46 \%)$ & $39(58 \%)$ & & $83(55 \%)$ & $139(61 \%)$ & \\
\hline$>4$ & $22(21 \%)$ & $1(1 \%)$ & & $21(14 \%)$ & $45(20 \%)$ & \\
\hline \multirow{2}{*}{\multicolumn{7}{|c|}{ Maternal height $(\mathrm{cm})$}} \\
\hline Mean & $152 \cdot 3$ & 153.6 & & & & \\
\hline SD & 5.6 & $5 \cdot 5$ & & 6.9 & 5.5 & \\
\hline$<150 \mathrm{~cm}$ & $32(32 \%)$ & $16(23 \%)$ & & $53(37 \%)$ & $52(24 \%)$ & $<0.02^{*}$ \\
\hline Height not known excluded & 6 & 1 & & 8 & 12 & \\
\hline
\end{tabular}

${ }^{*} \chi^{2}$ test (with Yates's correction, if appropriate); †Student's $t$ test; $¥$ Kolmogorov-Smirnov 2-sample test; P values $>0.09$ are not shown. 
Table 2 Influence of various factors on change in mean birthweight from 1968 to 1978

\begin{tabular}{|c|c|c|c|c|c|c|}
\hline \multirow[t]{3}{*}{ Factor } & \multicolumn{6}{|c|}{ Change in birthweight, $1968-78(\mathrm{~g})$} \\
\hline & \multicolumn{3}{|l|}{ Pakistani } & \multicolumn{3}{|l|}{ Indian } \\
\hline & $\begin{array}{l}\text { Attributable to change } \\
\text { in distribution of } \\
\text { factor since } 1968\end{array}$ & $\begin{array}{l}\text { Change not } \\
\text { accounted for }\end{array}$ & $\begin{array}{l}\text { Total } \\
\text { change }\end{array}$ & $\begin{array}{l}\text { Attributable to change } \\
\text { in distribution of } \\
\text { factor since } 1968\end{array}$ & $\begin{array}{l}\text { Change not } \\
\text { accounted for }\end{array}$ & $\begin{array}{l}\text { Total } \\
\text { change }\end{array}$ \\
\hline $\begin{array}{l}\text { Gestation } \\
\text { Parity } \\
\text { Height }\end{array}$ & $\begin{array}{l}23 \\
34 \\
16\end{array}$ & $\begin{array}{l}116 \\
105 \\
123\end{array}$ & $\begin{array}{l}139 \\
139 \\
139\end{array}$ & $\begin{array}{r}133 \\
-44 \\
26\end{array}$ & $\begin{array}{r}-108 \\
69 \\
-1\end{array}$ & $\begin{array}{l}25 \\
25 \\
25\end{array}$ \\
\hline
\end{tabular}

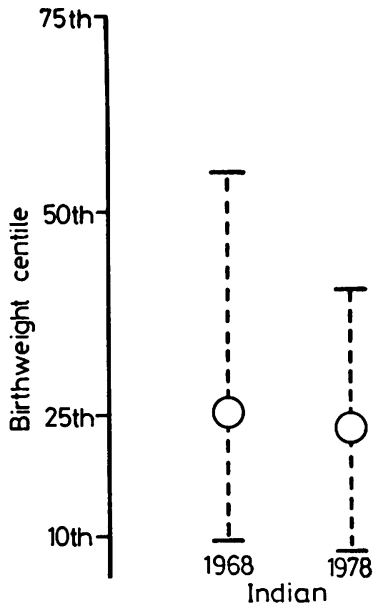

Indians. Indian women had longer gestations, and there were fewer very short mothers-both factors favouring a heavier birthweight_-but parity was much reduced.

The effects on birthweight of the changes in gestational age, parity, and maternal height have been studied in two ways.

(1) The 1978 distribution of births across each factor has been applied to the corresponding 1968 birthweights. This enabled us to estimate how much of the change in birthweight was attributable to changes in the distribution of each factor, and how much to changes in other things. The results are given in Table 2.

For Pakistanis, the interpretation is clear: changes in the distribution of each factor considered singly contributed only a small part (never more than one-quarter) to the overall change in mean weight between 1968 and 1978. The major reasons for the improved birthweight must therefore lie elsewhere, in particular in increased birthweight at each level of each factor.

The Indian experience is much more difficult to interpret, with no consistent pattern. Changes in gestational age would have tended to increase weight, but changes in parity would have tended to decrease it.

(2) Considering factors only one at a time takes no account of their combined effect. In order to do so, birthweights were expressed in terms of the birthweight centiles of Thomson et $a .^{7}$ and the two distributions of birthweight centiles were thus compared (Fig. 2).

Pakistani babies were on average heavier in 1978 than 1968, even after allowing for changes in gestational age, sex, parity, and maternal height, whereas Indian babies were slightly lighter, but neither of these differences reached statistical significance. In both 1968 and 1978 the birthweight centiles distribution in the Pakistanis was higher than in the Indians $(P \bumpeq 0.08)$.

Other variables affecting birthweight (Table 3). The length of time that the mothers had been in this country had increased but the average time was still fairly short ( 3.6 and 2.8 years) and some had been here for less than a year $(10 \%$ and $25 \%)$, Table 3 .

Inspection of the results showed that as in other 
Table 3 Other variables known to affect birthweight

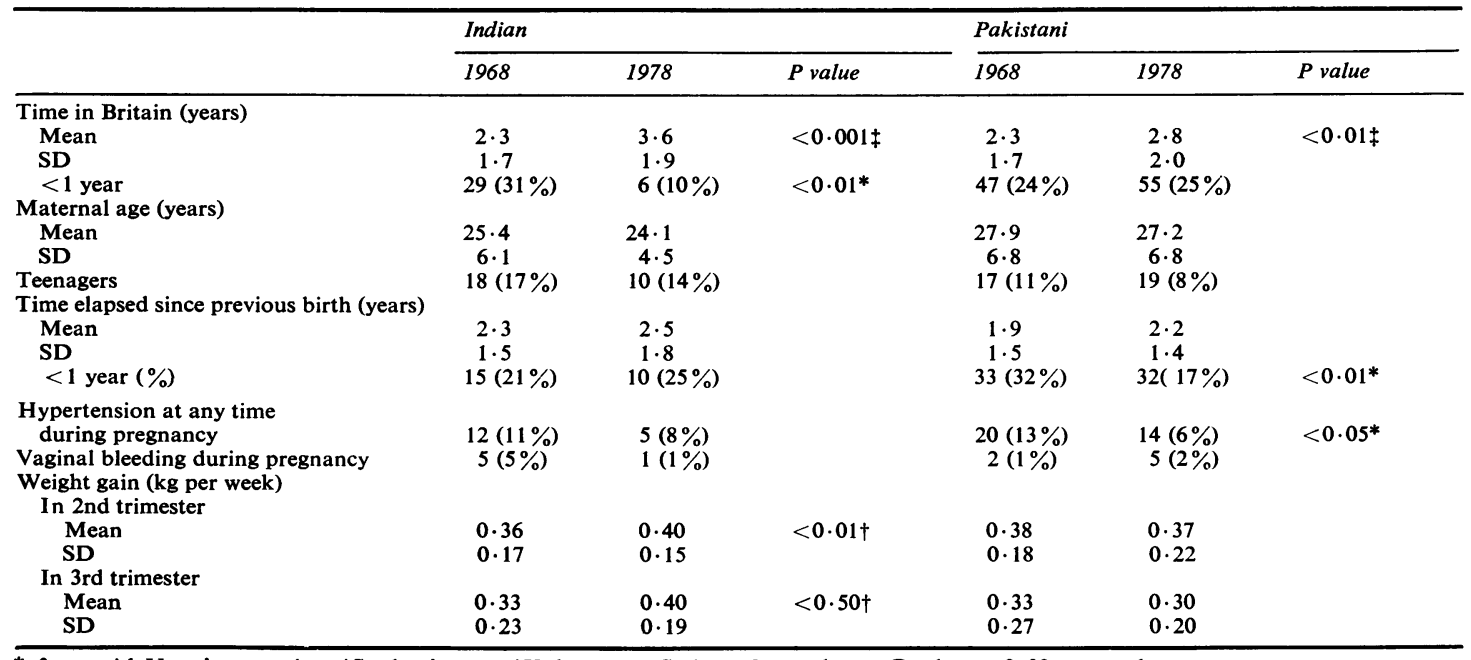

${ }^{*} \chi^{2}$-test with Yates’s correction; †Student’s $t$ test; $¥$ Kolmogorov-Smirnov 2-sample test; P values $>0.09$ are not shown.

populations, factors related to reproductive behaviour-for example short birth interval or teenage pregnancy-were associated with reduced birthweight in these Asian families. The changes in these two factors were therefore examined.

\section{Comparison between 1968 and 1978}

Pakistanis. There were fewer teenage pregnancies and a substantial reduction in the proportion of babies born within one year of the previous one.

Indians. There were fewer teenage pregnancies but the proportion of short birth intervals was slightly greater.

Hypertension was less common in 1978. In the Indians, mean weekly weight gain during each trimester was greater in 1978. None of the mothers smoked.

\section{Discussion}

Secular change and its causes. The increase during one decade of about $140 \mathrm{~g}$ in the weight of liveborn Pakistani babies is substantial, although their weight is still more than $140 \mathrm{~g}$ below the British overall mean. The longer pregnancies, particularly in the Indians, and the effect these had on birthweight, was unexpected, although the incidence of preterm births in both groups in 1978 remains somewhat above the overall British mean of $6 \%$.

It is unlikely that genetic factors have changed substantially during the 10 -year period, so that the observed changes are almost certainly due to alteration in the environment. In the Pakistanis the environmental changes have been in two directions: (a) improvement in the mothers' physical health in that fewer of them were very short, few had hyper- tension, and intrauterine growth, even after allowing for height and parity, was a little improved (NS); (b) changes in reproductive behaviour as shown by significantly fewer short birth intervals and fewer teenage pregnancies (NS).

The changes in the Indian population are difficult to interpret. There were fewer short mothers, suggesting some improvement in the physical? environment during their growing years, but intrauterine growth, after allowing for parity, height, and gestation, was no greater. In reproductive behaviour the number of very short birth intervals was no less. It seems that Indian mothers, while having fewer children than previously, nevertheless had them close together. Does the same birthweight, despite the longer gestational age, reflect the strains of the very short birth interval; or could it just possibly reflect a true genetic limitation in birthweight irrespective of gestation? This question can be answered only at a centre which has a much larger number of Indian births than we do at Sorrento.

Implications for clinical and community services. In practical terms, attempts to increase birthweight will clearly need to consider the mothers' physical environment during pregnancy; nutrition is one such factor in some Asian mothers at Sorrento. ${ }^{89}$ In addition however, the study suggests attention to factors before the pregnancy will also be necessary and may be more important--that is aspects of childhood environment which affect height, and those psychosocial factors which affect the age of first pregnancy, birth interval, and parity. The average length of time these mothers have lived in 
England is increasing (Table 3) and some of the changes may reflect this process of 'acculturation'for example the fewer short intervals between pregnancies in the Pakistanis, fewer teenage pregnancies. We hope that this process will not lead to smoking during pregnancy. There are implications here for child health, family planning, and health education services.

Sub-ethnic background. The results in the Pakistanis were very different from those in the Indians. The study demonstrates that the description 'Asian' to describe people originating from the Indian subcontinent is imprecise; for most purposes it will be necessary to give a more detailed description of the sub-ethnic mix. Differences in the sub-ethnic background of Asian communities in Britain may account for some of the apparently conflicting observations made concerning them.

Standards for intrauterine growth. There seems little point in setting up a standard of weight, or weight for gestational age for Asian babies. If such a standard were to be set up, which data would be used: the Sorrento Pakistani 1968 or 1978, the Sorrento Indian, or the Jaipur Indian (mean birthweight $2700 \mathrm{~g}$ in 1972) $?^{3}$ Although, as human biologists, we study data from different individuals at different times, ${ }^{1-6} 10$ the transmutation of the data into a plethora of standards for clinical or epidemiological use seems of doubtful value. Many authors have stated the case for a single set of reference data for postnatal growth. ${ }^{11-13}$ The same arguments could be made for a single set of reference data for intrauterine growth with which all infants, irrespective of race, geography, social circumstances, etc., may be compared.

We thank Miss J Hallum, Mr H M Mansfield, Mr P Needham, and Mr J Pogmore for allowing access to patients' notes; the Medical Illustration Department, Birmingham Children's Hospital, for preparation of the figures; Mrs $\mathbf{P}$ Cox and Mrs J Pickering for secretarial help.

\section{References}

1 Praharaj K C, Satapathy R K. Study of birth weight and its relation with gestational age and maternal factors. $J$ Ind Med Assoc 1975; 65: 97-101.

2 Gopalakrishnan R. Relations between gestation period and certain maternal and foetal factors. Ind $J$ Pediatr 1978; 45: 91-5.

3 Idnani N, Sharma U, Saxena S. Effect of maternal factors on the clinical features, morbidity, and mortality of the newborn. Ind J Pediatr 1979; 46: 75-86.

4 Wharton B A, Smalley C, Millns C, Nirmal J, Bissenden J G, Scott P H. The Asian mother and her baby at Sorrento. In: Wharton B A, ed. Topics in perinatal medicine. Tunbridge Wells: Pitman Medical, 1980: 141-51.

5 Arthurton M W. Immigrant children and the day-to-day work of a paediatrician. Arch Dis Child 1972; 47: 126-30.

6 Alvear J, Brooke O G. Fetal growth in different racial groups. Arch Dis Child 1978; 53: 27-32.

7 Thomson A M, Billewicz W Z, Hytten F E. The assessment of fetal growth. J Obstet Gynaecol Br Commonw 1968; 75: 903-16.

8 Bissenden $J$ G, Scott $P$ H, King J, Hallum J, Mansfield H N, Wharton B A. Anthropometric and biochemical changes during pregnancy in Asian and European mothers having light for gestational age babies. BrJ Obstet Gynaecol 1981 ; 88: 999-1008.

9 Viegas O A C, Scott P H, Cole T, Eaton P, Needham P G, Wharton B A. Dietary protein energy supplementation of pregnant Asian mothers at Sorrento, Birmingham. II. Selective during the 3 rd trimester only. $\mathrm{Br}$ Med $J$ 1982; 285: 592-5.

10 Brooke O G, Butters F, Wood C, Bailey P, Tukmachi F. Size at birth from 37-41 weeks' gestation: ethnic standards for British infants of both sexes. J Hum Nutr 1981; 35: 415-30.

11 Neumann C G. Reference data. In: Jelliffe D B, Jelliffe E P, eds. Human nutrition. Vol. 2. Nutrition and Growth. New York: Plenum, 1979: 299-328.

12 Waterlow J C. Letter: Child growth standards. Lancet 1980 ; i: 717.

13 Graitcer P L, Gentry E M. Measuring children: one reference for all. Lancet 1981 ; ii: 297-9.

Correspondence to Dr B A Wharton, Infant Development Unit, Queen Elizabeth Medical Centre. Edgbaston, Birmingham B15 2TG.

Received 9 August 1982 